\title{
stsing
}

\section{Doing STS In, Through And Beyond the German Academic System}

This manuscript is work in progress and feedback is very welcome.

\author{
Ingmar Lippert ${ }^{* 1,2,3}$, Julie S Mewes ${ }^{\dagger 4}$, Paula Helm ${ }^{\ddagger 5}$, Stefan Laser ${ }^{\S 6}$, Estrid Sørensen ${ }^{\mathbb{4}}$ and \\ Laura Kocksch ${ }^{\| 4}$ \\ ${ }^{1}$ Brandenburg University of Technology \\ ${ }^{2}$ IT University of Copenhagen \\ ${ }^{3}$ Museum für Naturkunde Berlin \\ ${ }^{4}$ Ruhr University Bochum \\ ${ }^{5}$ University of Tuebingen \\ ${ }^{6}$ Siegen University
}

October 5, 2021

\begin{abstract}
The recently constituted association stsing offers scholars a new platform to "do" STS in and through Germany (therefore the wording stsing). Specific about this platform is its creative and open understanding of collaboration on the one hand and critical reflection of national, international, institutional, and intergenerational challenges of STS research on the other. Germany's specific funding and institutional structure is of central importance to stsing. At the same time, stsing is responding to the internationally integrated practices of STS. It addresses the frictions between local bureaucracies and hierarchies as well as global doings and (self-)understandings of STS. We briefly unfold the (hi)story of stsing: a process of negotiating imaginaries, institutional settings,
\end{abstract}

\footnotetext{
*Ingmar.Lippertb-tu.de, @i_ngli

$\dagger @$ @ul_ie_m

$\ddagger @$ PaulaHelm12

$\S @$ stefan_laser_

I@estridsorensen

॥@datalora
}

conflicts and mutual recognition. The challenge is to open spaces and account for the heterogeneous people and disciplines engaged with the ideas, methodologies and politics of STS. stsing experiments with configuring infrastructures and organisational policies to support transnationally and interdisciplinarily oriented STS research practice. This experimentation works across generations and encounters troubles between and within generations of STS.

\section{Introduction}

Infrastructuring STS is a situated endeavour - regional and historically grown structures matter. This paper presents reflections on the process of establishing the newly founded association "stsing". stsing offers scholars and non-academics a new platform to collaborate and organize STS. On the one hand, stsing is a formal association ("Verein") according to German law. On the other hand lies at its heart the desire to experiment with organizational structures, e.g. German academic stiffness, methods and 
concept binaries, and neoliberal career logics. This requires creativity in finding an organizational form that operates in partial connection with the academic structures at hand (which many of us are a part of).

stsing proposes a case for the situated efforts to organize transnational STS while staying attached and responsive to a local academic system. To tell of this case, this paper engages in three modes. It narrates the German academic context that we react to in establishing stsing, describes how we build stsing in a way that is sensitive to, and critical of, this context and accounts for our commitment to experimentation and critique.

Building transnational STS must be attentive to local differences such as specific funding precarities and academic working conditions. Furthermore, it must take into account that STS multiplies on the ground of academic everyday practices: depending on disciplinary boundaries, historically grown interests, constellations of funding programs, etc. Locally, STS becomes more than one. The specific national conditions of STS matter - and counterintuitively, the national conditions do not deterministically generate singular and coherent effects - but also frictions and troubles, especially for a community facilitating transnational collaboration.

We proceed in the following steps. In section 2 , we plausibilise our claim that doing STS is also shaped by national contexts and structures. We proceed in section 3 by describing the German academic system. In section 4, we tell stories of the state and history of STS in Germany (without being able to account for its full complexity and multiplicity). In reaction, with section 5 , we spell out key critiques of the patterns of STS in Germany. Finally, in section 6, we elaborate on how we attempt(ed) to infrastructure STS differently within stsing - and point to some of the troubles we are currently facing while doing so.

\section{Doing STS}

Doing research on and with science and technology, including teaching efforts and third mission collaborations, is socially and materially shaped. Key to this are organisations and regulations, i.e. structures, or weaker forms of co-structuring agency. The academic system is socially embedded, can be context-driven and shaped. Governments and public authorities set important framework conditions for research topics and collaboration modes, also in terms of inter- and transnational connectivity. National and legal contexts matter, we have to draw on them, but we can also try flexing them. We know that these structures can be shaped. That they have to be challenged.

To plausibilise our claim that doing STS is also shaped by national contexts and structures, consider two brief examples: North America has a long tradition of critical ecological research, which is also critical of official data. Yet during the Trump administration, scholars from the social sciences and the STS context in particular assembled to "rescue" the data on environmental bads in the US context. The Environmental Data \& Governance Initiative (EDGI) was formed (Vera et al. 2019). The main focus here is on the Ministry of the Environment, with its multi-layered divisions and internal hierarchies that are not always transparent. Apart from being cautious and taking care of data, EDGI wants to do more: it works on prototyping new organizational structures and practices for distributed, collective, effective work rooted in justice. This is impressive. From this collective, we can learn to be sensitive to national context, explore how to carefully work with official data and legal structures while working toward a practice of transnational solidarity.

Let's move to a second example, from the UK, and much more thematically focused. Drawing on the spread of particular scientific knowledge in the public realm through production-consumption networks, the Nanodialogues "Demos" group aims to engage with the issue of nanotechnology. It organizes public events and wants to rethink democracy through experiments (cf. https://www.demos.co.uk). Nanodialogues is a discussion platform co-initiated by the government, but primarily led by the sciences, with additional critical monitoring by Demos. The topic of nanotechnology has intransparent consequences, so it is important to look at consequences from different perspectives and to make the performance of knowledge cultures visible, whilst being reflexive of how STS is enrolled in national and local nanotechnology 
agendas (cf. Joly and Kaufmann 2008). This is last not least an effort to transform institutions, to consider contexts that matter, linking everyday practices with new politics.

Both brief illustrations, the EDGI and the Demos group case, show how the engagement with science and technology is shaped by local and national contexts, although both can be related to transnational and global dynamics. We suggest there is much to learn from such cases regarding how we perceive and conceptualise STS as conducted within national and transnational scopes. National conditions play a role, but what role do they play in the German case?

\section{Academic practice within the German Academic System}

Next we address how the national conditions of an academic system can shape research. This section zooms in on Germany, the country in which the authors of this text are experimenting with organising STS infrastructures. We show that the academic funding system, common academic career paths and the role of professorships are important national infrastructures. Showing this system provides the ground for exploring in subsequent sections how our experience of this system and the position of STS in it informs the organizational form of stsing and its transnational orientation.

\subsection{Germany's academic funding sys- tem}

About $30 \%$ of Germany's universities are funded directly by the federal and state public sector. The remaining $70 \%$ are third-party funds from different German ministries, the European Union, namely the European Research Council, German companies and more than 5,000 foundations. The German Research Foundation (DFG) is the biggest third-party funder in Germany. Its purpose is to fund "Grundlagenforschung" or "scientific fundamental research" in a specific subject area (a disciplined field), accompanied by a reviewing process within that subject area (Research in Germany 2021).
Available funding sections are for instance "Social and Cultural Anthropology, Non-European Cultures, Jewish Studies and Religious Studies", and "Social Science" including "Sociological Theory" and "Empirical Social Research" (DFG 2021a). The DFG understands its categorising of funding sections (Fachkollegien) as interdisciplinary, the range of these interdisciplinary intersections, however, is quite narrow from the point of view of a range of interdisciplinary fields, such as sustainability studies, gender studies, postcolonial studies and other "studies" areas, including STS. DFG's decision-making is exceptional (in international comparison), with direct consequences for the availability and definition of these subjects.

DFG defines 49 subject areas, 12 for the social sciences and humanities. A subject area's review board is elected by postdoctoral academic staff of German research institutions. However, the candidates can only be scholars who are legally positioned as conducting independent research (primarily referring to professors, excluding, for instance, postdocs), and these candidates can be nominated by members (i.e. higher education institutions, etc.; but not by individual scholars).

DFG is governed by the research institutions themselves, rather than a ministry or corporations. The research institutions - including universities, scientific associations and non-university research institutions - form an assembly that "democratically" governs the funding body (DFG 2021b). These institutions have to be accredited by DFG, most universities of applied sciences (HAW) are therefore excluded from this funding opportunity which makes interdisciplinary research in the broader sense even more difficult (DFG 2021c).

\subsection{Academic careers in Germany}

What needs to change is the scholarly establishment itself. [...] Lone wolves, the constant willingness to work and the resulting overload, the over-identification with the activity itself, the dissolution of temporal boundaries, the requirement for spatial flexibility and mobility, the law on temporary 
scientific contracts, the almost exclusively fixed-term contracts, the feudal system of chairs and professorships, all these are factors that are not a prerequisite for good science. (Funke 2021, translation by authors)

The German academic system is special because it combines free-market competition (get funding and publish, stupid!) with a feudalistic structure. Faculties or institutes are typically organized into a few chairs, each held by tenured professors. The institutional structure and division in chairs - rather than departments - provides obstacles to distributing power or collectively sharing decision-making. Within a given chair, this may also lead to research closely linked to the interests and expertise of the chair and not so much representing the field as a whole (Waaijer 2015: 49). With professors having teaching responsibilities of 8-16 hours/week and additional administrative tasks and committee services to fulfil, the majority of research - and teaching - in fact, rests on the shoulders of non-tenured faculty.

Besides being the major workforce of research and teaching in German academia, $50 \%$ of early career researchers (pre- and postdoctoral) are employed on contracts termed shorter than one year; and in the social science and humanities, $50 \%$ of this group of researchers are employed part-time (GEW 2015; Schneijderberg and Götze 2020). In the default system, no permanent positions exist for German early career researchers (Laudel 2017). This leads to nontenured faculty chasing for contracts across the country and changing institutions and residency regularly. This becomes even more precarious for those with limited working permissions for whom the termination of a contract equals the termination of their residency permit.

The academic system's language signals its power relations. Traditionally, $\mathrm{PhD}$ supervisors are called "Doktormutter" or "Doktorvater"; doctoral "parents" to a "child-researcher". Non-tenured academic staff, early career researchers, often in their thirties or early forties, are referred to as "wissenschaftlicher Nachwuchs", literally "academic offspring", which modalises this group as not yet fully qualified for grown-up independent and self-guided research and teaching (cf. FRIAS 2021).

The national legal structure of the academic system does a lot of work in establishing pressure, causing mental and physical health problems in early career researchers (cf. Brasanac et al. 2021). Early career researchers, including $\mathrm{PhD}$ students and postdocs, are considered to be in their "qualification" phase. You get a job at the university where fulfilling this qualification is part of the job description. Yet due to this clause, you can only be employed for a limited amount of time (typically up to 6 years after a $\mathrm{PhD}$ degree). Qualification has a deadline, and as a result, almost every job at the university is based on a fixed contract. You can get or join third-party funded projects (which may also include qualification, just for the sake of it), which are limited by nature. As a result, the majority of academic researchers $(>92 \%)$ are employed precariously (i.e. no medium long term job security). Social movements criticise this injustice, and scientists are protesting with creative means (Bahr et al. 2021). On of the interview partners of Peacock (2016) conducting research in Germany illustrates the trouble:

The whole pressure is on the intermediate tier [postdocs, research group leaders]. Three to six years after completing your (doctoral) degree, you are expected to enter this intermediate tier. But up to ten years after completing your degree, you are expected to no longer be there. Because if you do get stuck there, there are legal issues and the MPI [the institution] has to take you on as a permanent employee which is not going to happen.

Protest against this situation so far has been only mildly successful in our opinion. In short, the general situation does not make academia the most desiring workplace. Internationally competitive researchers either are moving abroad to (seemingly) better conditions elsewhere or are leaving academia altogether. 


\subsection{On demands on professors in Ger- many}

Although career patterns are increasingly internationalised, career systems still are highly embedded into the specific national context (Finkelstein 2014). To be appointed a chair or professorship in Germany, applicants must show their ability to represent their field in its width and depth. Besides the necessity to hold a doctorate and a habilitation (the "second" book, or an "equivalent" achievement, like being granted an approximately one million EUR [1.2 million USD] grant for a small research group) this usually includes proving excellence in an entire discipline and at two of its subfields (Färber and Riedler 2016:122-125). Professorship positions are often announced as "successors" of retiring professors, which means that to be successful, it is helpful to work in similar areas and with similar theories as the retiring professor, which introduces a conservative trajectory in the development of the professorship.

Given the above-mentioned pattern of temporary positions for non-professorial academic staff, planning in the long-term - including for teaching, study programmes and strategic research foci - makes it attractive to appoint professors who complement the other professorships, but also to ensure the other professorships are not overloaden with tasks in the long term. Any new appointment needs to be strategically considered concerning how it can take on responsibilities to develop and represent the institute's discipline. If a chair is given to a novel field, even one coming susceptibly with forms of critical politics (gender, postcolonial, dis/ability studies, STS...), then the institute risks losing the professorship for its relatively conservative discipline.

The default job framework for a professorship is the "Beamtentum", a form of hiring professors as public servants, which is a form widespread in Europe (Bleiklie and Michelsen 2008). Practically, professors-as- "Beamte" in Germany cannot be fired by the state as they are not workers, and in return, the professors cannot go on strike and are bound in a relationship of fidelity to the state and the German people. The individual professor in this sense embodies the chair that serves the people. The responsibil- ity of the individual professor is for the chair, which includes its staff and resources. Maximising research and teaching performance in the short term can then be translated by the chair into a labour structure in which postdoc scholars are hired for a year only (to be flexible over time) or only at $50 \%$ of a full-time employee (as to employ in parallel two $50 \%$ workers who each individually is structurally conditioned to work at a maximum anyway).

In view of these remarks, we conclude that considering the local context and conditions of the academic system is important to understand how transnationalization efforts and inter-generational relations are locally configured. In the following we narrow the scope by showing how STS is tied in with local specificities in Germany, resulting in more than one STS.

\section{Stories of Patterns of STS, aka, Wissenschafts- und Technikforschung, in Ger- many}

Several attempts at writing the history of STS in Germany currently unfold (e.g. Bruksch and Wagner 2016), yet, in fact, there is no single narrative. From the outset, consider that in Germany, too, STS is associated with a range of disciplines (not limited to history, philosophy, sociology, social anthropology). From our perspective, STS must be perceived of as multiple, emerging form and being entwined with regional disciplinary peculiarities, and historically grown concept-methodological controversies. This section mobilises a multiplicity of narrating STS in Germany, as found in introductions and in the margins of scholarly material that we, the authors, associate with STS. Subsequently, how this characterisation of STS is shaped in specific German ways, will be addressed.

Lengersdorf and Wieser (2014) present STS in Germany as strongly influenced by the discipline of sociology. According to them, "for a long time" "institutionalist, differentiation- and system-theoretical as well as technology assessment approaches have been 
dominating" (4). One key centre in German social studies of science and technology was Bielefeld University until it was dismantled in 2012 . Its key proponent Peter Weingart draws on a Mertonian approach (cf. Weingart 2010), whilst following also some constructivist leads. However, by way of embracing Mertonian institutionalist analysis, this dominant branch of German STS implicitly positioned itself against SSK and the strong programme (cf. Potthast 2010:91; Kehl and Mathar 2014:111).

Resonating with the institutionalist-functionalist approach, German policy has been treating research on the institutions of higher education as a distinct field called "higher education research" (for instance by targeted funding through the Federal ministry of education and research, BMBF, in their 2010 call "Wissenschaftsökonomie" (BMBF 2010; cf. Pasternack 2015). From the perspective of this higher education research, science studies belong to its space, but not technology studies (Winter 2014:38).

The sociology of technology is enacted as significantly distinct from sociology of science, even though both "special" sociologies are institutionally joined in both the dominant German sociological association's (DGS) subunit for the sociology of science and technology and in the association for science and technology studies, GWTF, which was founded in 1987 (Strübing 2003:563). Lengersdorf and Hörning (2014) reconstruct the emergence of a sociology of technology in Germany. Their account foregrounds the degree to which post-structuralist work has been opposed in German sociology of the 1980s. Latour's thinking was considered "exotic" (Lengersdorf and Hörning 2014:10); and Luhmann's system theory was considered state of the art in German sociology, leading to countless comparative papers between Luhmann and Latour. From Hörning's perspective, a sociology of technology was soon embracing relational and processual analytics, to study how technologies were interactionally interpreted, assigned meanings and also shaping the definition of what counts in situated action. However, this kind of analytics did not resonate well with the institutionalist-functionalist analytics, dominating the sociology of science.

The history of science and technology in Germany consists of myriad organisations and associations -
Saatz and Wahrig (2017) list these across 19 pages, and counts as relevant, too, GWTF. GWTF has held a joint conference together with the association for the history of science (GWG) back in 2011.

German social anthropology's relation to STS is discussed by Niewöhner et al. (2014). Their introduction presents social anthropologically inclined STS as shaped by the international state of the art of praxeographic ethnography that is not particularly informed by German scholarship. A group of Germany based social anthropologists engaged in STS has been foregrounding that the existing STS networks in Germany are not representative of scholars engaging in international STS conversations (Niewöhner 2018; Mewes 2019).

Technology assessment has been institutionalised with an office at the German parliament, Bundestag (TAB), since 1990, which is run by Karlsruhe Institute for Technology. However, the discussion leading up to its foundation reaches back to the 1970s (TAB 2021). Whilst the formal political process took two decades, politically engaged researchers have been organising overtly political analyses of science and technology since the 1970s, too (for instance the yearly Women in Natural Science and Technology Congress (FiNuT) dates back to 1977). The German association for political science (DVPW) has by now also set up its distinct working group on politics, science and technology.

This sketch of STS indicates a pattern of a largely disciplinary organisation of STS in terms of "classical" disciplines. It is not possible to do justice in a few words to the more than a dozen organisations that are currently committed to different STS-like perspectives alone. As little as in this pattern is space for institutionalising interdisciplinary STS research in the long term, as little was in this pattern space for significantly integrating the experience of conducting STS research in the German Democratic Republic (even though some of that was evaluated as being of high quality, Schütze 1997). Yet, the distribution of STS across disparate disciplinary (sub)fields can be considered as securing a form of knowledge pluralism.

The formation of STS as an interdisciplinary field in Germany was shaped by the foundation of GWTF in 1987. In the narration by "Arbeitsstelle Kleine 


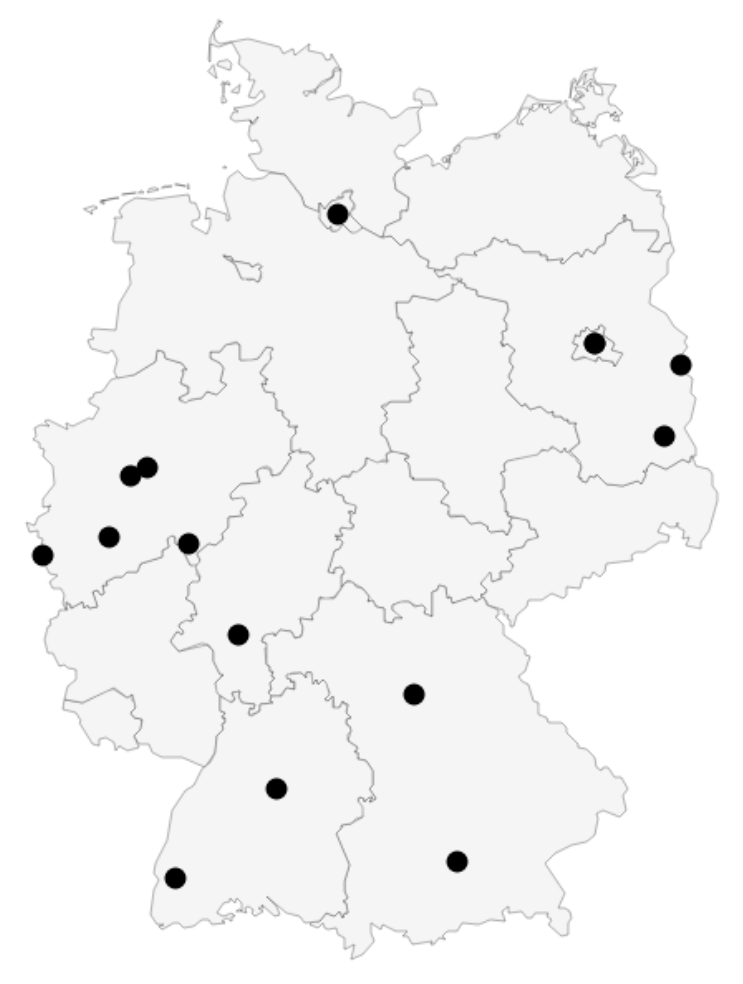

Figure 1: Distribution of STS Professorships

Fächer" (2020), a first professorship for STS was appointed in 1994. And, in their account, the field has grown swiftly recently, with, since the late 1990s, the number of professorships having risen with currently 18 professorships across 14 universities as shown on the map. Only a couple of years ago, the first STS $\mathrm{MA}$ and $\mathrm{PhD}$ programs were initiated (Mewes 2019).

The highly disciplinarily patterned STS in Germany can be theoretically explained by the way professorships and research funding are distributed. An empirical indication of this link can be found in Hörning's account (Lengersdorf and Hörning 2014: 16): the national research funding organisation DFG has reacted in the early 1980s to a perceived crisis of the modern German society (increasing unemployment and stronger Asian, specifically Japanese, economic competition). In reaction, DFG set up a funding scheme for social science research into technology. In meetings for this scheme, it became clear that the sociologies of industry and organisations were to conduct this research. That DFG scheme did not call for interdisciplinary research.

A different form of political shaping of STS in Germany is indicated in cases of transdisciplinary research. Consider research into higher education: it is set up and funded to conduct research that supports higher education policies and problem-solving (Teichler 1996: 434-6).

This section plausibilises to understand STS in Germany not as singular (subsequently also not in transnational endeavours), but multiple and as locally enacted in varying disciplinary and conceptmethodological controversies. With this we articulate a controversial and plural history of STS. Transnationalization efforts must take into account this historicity and multiplicity.

\section{A critique of the German academic system, and of STS as it is organised in Germany}

This section points to the problems of STS in Germany so far - primarily developed in friction with sociologically disciplined studies of science and technology. This section argues why something should change, building on authors' key experiences. The subsequent section (6) then explains how we organised to enact and prefigure these changes.

\subsection{Inter/Disciplinarity?}

While US and EU funding schemes recognise STS as a field, most national funding schemes in Europe do not include STS as a (trans)disciplinary category. STS scholars are thus challenged to strategically write funding applications that fit the disciplinary categories of the funding organisations; while interdisciplinary STS research applications face disciplinary domination (Lengersdorf and Wieser 2014:4). Colleagues also experience the need to underplay the STS context of their work, as a certain hostility is experienced towards the field by some reviewers. However, other STS scholars are overly successful in ap- 
plying for funding, which tends to indicate that these challenges are not necessary deterministic obstacles. A larger challenge appears to be that STS scholars increasingly work in larger consortia with both social and technical or natural scientists. This turns out to be a challenge when submitting applications to a disciplinary funding section since these tend to be reluctant to fund scholars from other disciplinary areas. There are currently debates in Germany about whether establishing an STS funding category in the largest national funding institution, DFG, is desirable and/or a meaningful strategic objective. If STS was a recognised field, this might help STS applications to be assigned reviewers with an STS qualification. However, one of the habitual roles of STS in the academic landscape, to both interact with and irritate disciplinary thinking, would likely be diminished. Some voices even fear that if STS is put into an institutionalized box, it's innovative and creative potential - which emerges from its marginal position in friction with disciplines - may be risked. Trans/Nationality?

As the (hi)stories of the studies of science and technology in Germany above make clear, we perceive a strong tradition for both sociological and political studies of science and technology. Generally, the involved scholars are situated at German institutions and they draw strongly on German-speaking literature. A call for a new organisation and a differently infrastructured community emerged in response to German STS scholars collaborating internationally. One of the internationally most acknowledged German-speaking STS scholars is Karin KnorrCetina from Austria, who in later years of her career however oriented herself towards her US-American collaborators rather than prioritising the integration of her work into a German disciplinary context.

Maybe because of the strong German tradition in social studies of science and technology, experts in these traditions often reject internationally working STS scholars' studies. Though the latter attend to similar empirical phenomena as the former, and with overlapping sensitivities, from the perspective of the German sociological and political studies take on S\&T, international STS scholars tend to (a) draw on supposedly non-German, i.e., different, con- cepts and (b) refer to different literature. Sometimes social scientists in Germany also have reservations about STS's experimental (conceptual) language (a phenomenon also recognised internationally, reminiscent of the "high church" vs. "low church" issue; cf. Fuller 1997; Sismondo 2007). Internationally and interdiscplinarily working STS scholars who become acquainted with STS tend to be marginalised by classically disciplined German colleagues with the argument that there is a German tradition which they should attend to (first). We perceive this argument as a barrier to conducting inter- or even transnationally oriented and interdisciplinary STS research. Due to this opposition, internationally working STS scholars in Germany increasingly felt the need to form their own community, characterised by its international influences.

Forming a new, and an "own" community - stsing - grew (also) out of practical circumstances. In hindsight, however, it does seem symptomatic that the first meeting towards founding stsing took place outside of Germany, at the 2018 EASST meeting in Lancaster (Niewöhner 2018). This provoked critiques from colleagues who did not attend the meeting and thus felt excluded. However, for the new STS community emerging in Germany, EASST and 4S meetings are probably where they meet their core networks, also of German scholars. However, this criticism was met by us with an open call for an organising meeting in Kassel, Germany, which took place in early 2019 (Bogusz et al. 2019).

It is similarly interesting that these internationally working STS scholars early on decided that English should be their working language. This is to make sure to integrate the non-German speaking STS colleagues in Germany, but it also underlines the understanding of the international English speaking scholarly community to be their main point of reference. This also means that different Heroes and Heroines are celebrated - and with them different discussion cultures and different academic values. Even if this is rarely meant as an explicit rejection of the German tradition, it in practice comes to be perceived as such regularly. A challenge for these internationally working STS scholars is to build bridges and passages between the German and German speaking traditions 
and literature and the English language STS community.

\subsection{Generations?}

The relationship between versions of internationally oriented STS and versions of STS enacted through the classical German disciplines intersects with generational matters. The key issue is the question of the reproduction of (inter)disciplinary traditions. Two interrelated concepts of generation are at play in this discussion. One concept refers to generations of research (ideas, concepts, methods, methodologies, disciplinarity), the other refers to generations of researchers as embodied humans.

The framing of building bridges across these multiple versions of the social studies of science and technology may intuitively invite a vision of a friendly encounter between islands (for the islands metaphor, see Jasanoff 2017). However, from the perspective of a conservative discipline institutionalised at an institute, building bridges to a primarily internationally oriented STS can also risk an invasion. A discipline's chair might get lost to "STS" when it is not appointed to a proper, say, "sociologist" or "ethnologist".

For an institute to hire a primarily internationally oriented STS scholar as a professor therefore seems unlikely. No generational shift is to be expected in this respect. However, for already established classical professorships, hiring STS scholars as early career researchers can be a form of rational and safe bridge-building. Such a safe STS scholar can then also be safely tasked to offer STS teaching in minors, and majors (which we increasingly see in Germany), without risking to generate demand for instituting STS at programme level (which is still rare in Germany). New generations of internationally and interdisciplinary oriented students of STS are, however, unlikely to grow well under such a classically disciplined conditions.

Those early career researchers who are hired by established disciplinary generations (and their professors) can offer STS taste and posture to well established disciplinary processes; tacit as well as explicit internationally oriented STS scholarship is mobilised (cf. Collins 1974) to perform an engagement with
STS within the classical discipline (cf. Wiedmann et al. 2020; Lippert 2020). However, as such early career scholars are typically on temporary positions and cannot be hired permanently (if they are not given a professorship, an unlikely case), the scholar cannot enact a generational shift of approach towards an transnationally and interdiscplinarily oriented social study of science and technology.

The strategic problem then involves figuring out ways of developing triple qualifications. Where Potthast (2010:92) identified STS scholars in Germany as coming with dual qualifications (in a discipline that is studied and a discipline [in our case, the field of STS] that provides methods, theories that are employed to analyse the object), the early career researcher who is oriented at international and interdisciplinary STS scholarship has to enact a third qualification in a classical German discipline.

In short, given the described tensions between competing versions of science and technology studies in Germany, the vision of an intergenerational STS faces the reproduction of a conservative disciplinary generation. In addition to the strategy of establishing inter- (or even trans)national and interdisciplinary STS professorships within the German academic system, the issue of working conditions for young scholars needs to be adressed.

In light of these critical analyses, we, the authors, have worked to support the transnational and interdisciplinary English-language STS community in Germany. The stsing organization serves to crystallize this investment.

\section{6 stsing as a complementary or interventive organisational contribution}

stsing is inspired by a grassroots democratic impulse. This impulse grew out of the idea of creating around STS a nationally situated but internationally oriented academic community (Niewöhner, Sørensen and Bogusz 2021). As a practical expression of its international orientation, stsing has declared English to be its lingua franca, and several of 
its bodies have committed to conducting texts and conversations bilingually. However, given the hierarchical and sometimes quite conservative structure of German academia, coupled with the methodological individualism of German association law, the implementation of such an impulse is certainly not without friction (Tsing 2011). Nevertheless: stsing is a German association and well over $70 \%$ of its members are employed in the German academic system. And this is no coincidence. Rather, the point is precisely to enact stsing not in opposition to the given structures, but in partial connection with them (Strathern 1991). This implies constant troubles. Following Donna Haraway (2016), we have decided to stay with them.

\subsection{Troubles in (not) being active within stsing and vis-à-vis the le- gal environment}

stsing is a formal association according to German law. This organizational form of the "Verein" allows to side-step conventions in academia, e.g., it is not limited to those with current contracts or enclosed for specific disciplines, but also generates troubles for a community with a commitment to experimentation and alternative hierarchies. We report on some of the frictions that lie within operating as a formal association.

Signing documents in the context of establishing and maintaining a German association is often not only an isolated, official act but entails approaching the person who signed every time something arises that requires someone to be approached. Usually, it is the officially elected board members or chairs who have to sign legal documents and thus take on increased responsibility. This brings with it certain problems because, in order to counteract the intergenerational power asymmetries at German universities, stsing has enshrined in its statutes that 3 of the 7 board members must be pre-doc early career researchers. This creates an ethical dilemma: while it seems important to soften hierarchies and rigid structures and give those in precarious situations a stronger voice in the long-term shaping of the Ger- man academic landscape, it is also somewhat unethical to involve those in unpaid labour who are already struggling with the pressures of fixed-term contracts and the often conflicting demands during the $\mathrm{PhD}$ phase.

We identify another friction - this time between German association law and stsing's cosmopolitan orientation. Law-in-practice means that certain offices can only be held at all by people who either have a German passport or a permanent visa. Unfortunately, though and despite an increasingly pluralistic, cosmopolitan research landscape, permanent visas are still anything but straightforward for people working in the German academic system.

In general, it can be said that the default setting anchored in German association culture is both nationally oriented and individual-centred. It takes special effort and awareness to subvert this culture. One of stsing's concrete attempts to do this is not only to be bi- or even multilingual and to promote (intergenerational) equity in the form of a diverse board and membership but also to challenge the traditional role of the board in the first place. Instead of being the centre or even the head, in stsing, the board is to be understood as a kind of infrastructural service unit (Helm, Kocksch and Sørensen 2021). This unit ensures that the association can function as it needs, so that the working groups, which are the real core, can work well under a common roof.

stsing's working groups are its declared heart. They run on a non-binding basis. Whether they are active depends solely on who is currently filling them with life. This, in turn, is not free of trouble either, because it can lead to the start of a vicious circle if working groups are inactive. When this is the case, the board is called upon to ensure that important processes function. This can lead to even more centralization of responsibility on the board (e.g., signing more documents, making decisions, being the ones who know how processes work), and the working groups pull back. One of the driving questions in the doing of stsing is therefore: How can the working groups be strengthened and the board kept out of the centre? 


\subsection{The case of the best practice group}

Of stsing's current nine more or less existing, more or less active, working groups, one is the so-called "best practice group". This group is crucial for an initiative like stsing. It engages, inter alia, with issues of racism, sexism and colonialism (thus, the name does not seek to refer to managerial discourses of "best practice"). However, over the last year, the best practice group has shrunk from eight to three active members, one of whom is now also a member of the board. Additionally, in its internal discussion, it came to the conclusion, that the best practice group should be formally elected first in order to indicate clearly that the individuals working on such fundamental issues for the association have a formal mandate to do so. Nevertheless, in the meantime in an organizational form like stsing's, there are important tasks that need to be done by the best practice group, such as drafting a code of conduct or proposing an anti-discrimination paragraph for the statutes. Without these foundations, the board must make decisions on ethical issues either intuitively or on its initiative. This concerns, for example, the choice of the bank, the conditions under which membership applications are rejected or members are excluded.

The current discussion of the $4 \mathrm{~S}$ Council and the withdrawal of some of its members is informative in this regard (see the statements of Noortje Marres and Anna Viseu about their resignment from the $4 \mathrm{~S}$ council, 2021). The 4 S Council has also written a manual driven by the conviction that some kind of "code of conduct" is needed. stsing is attempting something similar with the statute and the accompanying (public) document explaining the motivations and discussions behind the wording of the statute. However, this document is still a work-in-progress and will require eager minds and hands to complete. Yet what is such a document worth on its own? It must be lived, it must be put into practice, and it must also remain flexible and adaptable to situational requirements. How can such a thing work? Can a code be flexible? Isn't that a contradiction in terms?

There is another more operational question posed by this process: Doesn't the idea of formally and cen- trally electing the members of the working groups in certain cases like that of the best practice group spoil the initial idea of the working groups being the selforganized, rhizomatic heart of stsing? Or is it a pragmatic and quite wise way of dealing with the problem that voluntary self-organization, while sometimes producing the most fruitful results, is unpredictable and in the end you never know in which direction it will develop - whether it will simply dissolve. And then what? Perhaps making ethically relevant decisions spontaneously and from the gut is not such a bad thing after all, as it speaks to the often rushed and messy reality of non-universal, situated ethopolitics (Ammicht Quinn 2015; Puig de la Bellacasa 2017; Tronto 2012). Nonetheless, we feel we must care not to make mistakes that are difficult to undo, leaving stains or even scars.

\subsection{Troubles of labour}

Labour relations are not merely something that are determined by the structure of the German academic system, but these relations are also configured by members of stsing who embody chairs, who take on formal and practical responsibility for the support of STS scholars. stsing has been joining up with other associations in Germany in voicing protest against unsustainable working conditions for early career researchers (cf. Bahr et al. 2021). Beyond this critique of the existing structures, our members have partial agency in devising labour relations in situated teams, work relations and dependencies.

Two sets of objectives are of interest. First, as an association, stsing has to take an active role in advocating for better work conditions and for futures that are more reliable for non-tenured researchers. As part of this, we have to act as a multi-sited networking space for STS researchers to connect and making their research and their interests being noticed. This also includes the matter of transgenerational learning and solidarity. To prevent (or soften) frictions between generations of researchers, or namely nontenured and tenured academics, we need to understand the specific challenges and needs of both groups and act as a united interest group in front of funding bodies and institutions. 
Second, as a community, we need to address how we prefigure the desired changes within our own workspaces. Enacting solidarity among researchers in different stages of their careers includes cutting "family ties" that reproduce dependency (expressed in the notions of "Doktorvater") and find novel ways of relating to (and speaking about) each other. It also includes caring for good work conditions, fulltime employment, minimizing working overtime and contracts allowing to finish the project, thesis, or habilitation. stsing has not yet established a code of labour conduct that would demand such prefigurative action by its members. The trouble is that stsing wants to work transgenerationally but the different generations (even within the internationally and interdisciplinarily oriented STS scholarship) are also interested parties in devising their chair's labour structure, translating economic conditions of the chair into STS labour.

\section{After the critique, infrastructur- ing in process}

It is too early to draw major conclusions here. Except perhaps that the idea of stsing as a grassroots form of an organization depends on enough people doing it. And if there are hang-ups, then we need to stay flexible, deviate from our plans, act situationally. That, too, is part of the idea and practice of stsing, which calls for feedback loops inside its rhizomatic structure. This way we can stay true to the reflexive turn we embrace, yet staying alert to keeping stsing as unbureaucratic and decentralized as possible.

\section{References}

Ammicht Quinn R (2015). Trust Generating Security Generating Trust: An Ethical Perspective on a Secularized Discourse. Behemoth. A Journal on Civilization 8(1), 109-25. https://doi.org/10.6094/ behemoth.2015.8.1.855.

Arbeitsstelle Kleine Fächer (2020). STS - Science and Technology Studies, Accessed on 29.09.2021, https :

//www.kleinefaecher.de/kartierung/ kleine-faecher-von-a-z.html?tx_dmdb_ monitoring [disciplineTaxonomy] $=153 \&$ cHash=32cf0f8ea9666fa034bd9e48bf 482cd7

Bahr A, C Blume, K Eichhorn and S Kubon (2021). With \#IchBinHanna, German academia protests against a law that forces researchers out. Nature Human Behaviour, 5(9), 1114-5. https:

//doi.org/10.1038/s41562-021-01178-6

Beck S, J Niewöhner and E Sørensen (eds)(2012). Science and Technology Studies: Eine sozialanthropologische Einführung, 17. transcript.

Bleiklie I and S Michelsen (2008). The University as Enterprise And Academic Co-Determination. In Amaral A, I Bleiklie and C Musselin (eds) From Governance to Identity. Higher Education Dynamics 24, Springer. https://doi.org/10.1007/978-1-4020-8994-7_6

Bundesministerium für Bildung und Forschung (BMBF) (2010). Bekanntmachung des Bundesministeriums für Bildung und Forschung von Richtlinien zur Förderung von Forschungsvorhaben zum Themenfeld "Wissenschaftsökonomie". https://web. archive.org/web/20130517062318/http: //www.bmbf.de/foerderungen/14677.php

Bogusz T, S Büchner, E Dányi, A Klein, S Laser, M Schlünder and E Sørensen (2019). \#stsing but how? An open workshop on possible 
organisation forms of STS-in-Germany, 20.-21.02.2019 at Kassel University. https: //web.archive.org/web/20201025125507/ https://stsingermany2019.com/archiv/ workshop-report/

Brucksch S and C Wagner (2016). Introduction to the Technikstudien- Science and Technology Studies (STS) Research Initiative on Japan. ASIEN 140,5-21. https://web.archive. org/web/20170109100419/http: //asien.asienforschung.de/wp-content/ uploads/sites/6/2016/10/ASIEN_140_ Brucksch_Wagner.pdf

Brasanac J, R Haas, C Hartling, M Kikhia, E Matthaei and AS Oliveira Gonçalves (2021). To the presidents of the BUA universities. Open letter, Berlin 25.02.2021. https : //www.tagesspiegel.de/downloads/ 26952490/2/offenerbrief .pdf

Collins, HM (1974) The TEA set: Tacit knowledge and scientific networks. Science Studies 4(2), 165-85. https :

//doi.org/10.1177/030631277400400203

Deutsche Forschungsgemeinschaft (DFG) (2021a). Review Boards. https://www.dfg.de/en/ dfg_profile/statutory_bodies/review_ boards/list/index.jsp\#contentTop

Deutsche Forschungsgemeinschaft (DFG) (2021b). What is the DFG? https://web.archive. org/web/20210927073350/https : //www.dfg.de/en/dfg_profile/mission/ what_is_the_dfg/index.html

Deutsche Forschungsgemeinschaft (DFG) (2021c). Mitglieder der Deutschen Forschungsgemeinschaft. https://www.dfg.de/dfg_profil/gremien/ mitgliederversammlung/mitgliedskarte/ index.html

Färber C and Riedler U (2016). Black Box Berufung: Strategien auf dem Weg zur Professur, Campus Verlag.

Fuller S (1997). Constructing the high church-low church distinction in STS textbooks. Bulletin of Science, Technology $\&$ Society 17(4), 181-3. https : //doi.org/10.1177/027046769701700408

Funke J (2021). Die gesamte wissenschaftliche Praxis muss sich ändern. . . Ein Interview mit den Herausgeberinnen der Publikation: Mutterschaft und Wissenschaft. Die (Un-) Vereinbarkeit von traditionellem Mutterbild und wissenschaftlicher Tätigkeit, Zeitgeschichte-online. https://web. archive.org/web/20210310060329/https : //zeitgeschichte-online.de/interview/ die-gesamte-wissenschaftliche--praxis-muss-sich-aenc

Finkelstein M (2014). How Does National Context Shape Academic Work and Careers? The Prospects for Some Empirical Answers. In Maldonado-Maldonado A and R Bassett (eds) The Forefront of International Higher Education. Higher Education Dynamics, 42, Springer. https :

//doi.org/10.1007/978-94-007-7085-0_3

Freiburg Institute of Advanced Studies (FRIAS)(2021). Interview: Die Macht sozialer Umgangsformen. https://web. archive.org/web/20210928183310/https :

//www.frias.uni-freiburg.de/de/ aktuelles/mitteilungen-aktuell/ die-macht-sozialer-umgangsformen

Gewerkschaft für Erziehung und Wissenschaft (GEW)(2015). GEW initiative on the verge of a breakthrough: reform of limited-term employment contracts in academia imminent in Germany.

https://www.ei-ie.org/en/item/19995: gew-initiative-on-the-verge-of-a-breakthrough-reforr

Haraway D (2016). Staying with the Trouble: Making Kin in the Chthulucene. Duke University Press.

Helm P, L Kocksch and E Sørensen (2021). Staying with the troubles of infrastructuring stsing: between assemblage and "Verein". EASST Review 40(2). 
Jasanoff S (2017). A Field of Its Own. The Oxford Handbook of Interdisciplinarity, Oxford University Press, 173-87.

Joly PB and A Kaufmann (2008). Lost in translation? The need for "upstream engagement" with nanotechnology on trial. Science as Culture, 17(3), 225-47.

Kehl C and T Mathar (2014). Eine neue Wissenschaftssoziologie: Die Sociology of Scientific Knowledge und das Strong Programme. In Beck S, Niewöhner J and E Sørensen 2014, 103-22.

Laudel G (2017). How do National Career Systems Promote or Hinder the Emergence of New Research Lines? Minerva 55, 341-69. https : //doi.org/10.1007/s11024-017-9314-4.

Lengersdorf D and KH Hörning (2014). "Wir saßen alleine am Katzentisch" - Zur

Hervorbringung der Techniksoziologie in Deutschland. In Lengersdorf and Wieser 2014a, 9-19.

Lengersdorf D and M Wieser (eds)(2014a). Schlüsselwerke der Science \& Technology Studies, VS Verlag für Sozialwissenschaften. https://doi.org/10.1007/978-3-531-19455-4.

Lengersdorf D and M Wieser (2014b). Über die (Un-)Möglichkeit eines Schlüsselwerks der Wissenschafts- und Technikforschung. In Lengersdorf and Wieser 2014a, 3-7.

Lippert I (2020). In, with and of STS. In Wiedmann A, K Wagenknecht, P Goll and A Wagenknecht (eds), 301-18.

Marres N and A Viseu (2021). Why we resigned from $4 \mathrm{~S}$ Council. http:

//noortjemarres.net/index.php/2021/09/ 23/why-we-resigned-from-4s-council/ and http://anaviseu.org/in-action\# /resignation-from-4s-council/

Mewes JS (2019). "Stsing" - Towards inclusive forms of STS-in-Germany, EASST Review 38(2), https://easst.net/article/ report-stsing-towards-inclusive-forms-of-sts-in-gerr

Niewöhner J on behalf of the committee (2018). STS in Germany: Ve vill go on!, https://www.dests.de/wp-content/ uploads/2018/08/STS-in-Germany-\OT1\ textendash-Ve-vill-go-on.pdf

Niewöhner J, E Sørensen and S Beck (2012). Einleitung: Science and Technology Studies aus sozial- und kulturanthropologischer Perspektive. In Beck, Niewöhner and Sørensen 2014, 9-48.

Niewöhner J, E Sørensen and T Bogusz (2021). The Cosmology of stsing. EASST Review 40(2).

Pasternack P (ed) (2014a). Hochschulforschung von innen und seitwärts: Sichtachsen durch ein Forschungsfeld. Sichtachsen durch ein Forschungsfeld, die hochschule 1/2014.

Pasternack P (2014b). Reload oder Reboot? Hochschulforschung in der Diskussion. In Pasternack 2014a, 6-24.

Peacock V (2016). Academic precarity as hierarchical dependence in the Max Planck Society, HAU: Journal of Ethnographic Theory, 6(1), 95-119

Puig de la Bellacasa M (2017). Matters of Care: Speculative Ethics in More Than Human Worlds. University of Minnesota Press.

Potthast J (2010). Science and Technology Studies. In Simon, Knie and Hornbostel 2010, 91-105.

Research in Germany (2020). Research funding system, https://www.research-in-germany.org/ en/research-funding/ research-funding-system.html

Saatz J and B Wahrig (eds)(2017). History of Science, Technology and Medicine in Germany 2013-2016. Technical report. https://doi.org/10.24355/DBBS. 084-202108300848-0

Schneijderberg C and N Götze (2020). Organisierte, 
metrifizierte und exzellente

Wissenschaftler*innen. Veränderungen der Arbeits- und Beschäftigungsbedingungen an Fachhochschulen und Universitäten von 1992 über 2007 bis 2018. Report.https:

//doi.org/10.5281/zenodo.3949756

Schütze W (1997). Lebendigkeit der

Wissenschaftsforschung - zum Beitrag des Instituts für Theorie, Geschichte und Organisation der Wissenschaft (ITW) der AdW der DDR. In H Betram (ed). Soziologie und Soziologen im Übergang: Beiträge zur Transformation der außeruniversitären soziologischen Forschung in Ostdeutschland, Leske + Budrich, 115-26.

Simon D, A Knie and S Hornbostel (eds)(2010). Handbuch Wissenschaftspolitik. VS Verlag für Sozialwissenschaften.

https://link. springer.com/book/10. 1007/978-3-531-91993-5.

Sismondo S (2007). Science and Technology Studies and an Engaged Program. In EJ Hackett, O Amsterdamska, M Lynch and J Wajcman (eds) The Handbook of Science and Technology Studies. MIT Press, 13-31.

Strathern M (1991). Partial connections. Rowman and Littlefield.

Strübing J (2013). Von ungleichen Schwestern: Was forscht die Wissenschafts- und (was die) Technikforschung? In B Orth, T Schwietring and J Weiß (eds). Soziologische Forschung: Stand und Perspektiven, Leske + Budrich, 563-79. https://doi.org/10.1007/ 978-3-322-95017-8_37.

Technology Assessment at the German Bundestag (TAB)(2021). TA at the German Bundestag: A brief history of the Office of Technology Assessment at the German Bundestag (TAB). Accessed 24 September 2021. https://web. archive.org/web/20210924195442/https: //www.tab-beim-bundestag.de/en/ about-tab/history.html.
Teichler U (1996). Comparative higher education: potentials and limits. Higher Education 32(4), 431-65.

https://doi.org/10.1007/bf00133257.

Tronto J (2013). Caring Democracy: Markets, Equality, and Justice. New York University Press.

Tsing A (2004). Friction: An Ethnography of Global Connection. Princeton University Press.

Vera LA, D Walker, M Murphy, B Mansfield, LM Siad and J Ogden (2019). When data justice and environmental justice meet: Formulating a response to extractive logic through environmental data justice. Information, Communication \& Society, 22(7), 1012-28. https : //doi.org/10.1080/1369118X . 2019. 1596293

Waaijer CJF (2015). The Coming of Age of the Academic Career: Differentiation and Professionalization of German Academic Positions from the 19th Century to the Present. Minerva 53(1), 43-67.

Weingart P (2010). Wissenschaftssoziologie. In Simon, Knie and Hornbostel 2010, 118-29.

Wiedmann A, K Wagenknecht, P Goll and A Wagenknecht (eds)(2020a). Wie Forschen mit den "Science and Technology Studies"? Interdisziplinäre Perspektiven. transcript.

Wiedmann A, K Wagenknecht, A Wagenknecht and P Goll (2020b) Wie Forschen mit den "Science and Technology Studies"? In Wiedmann A, K Wagenknecht,P Goll and A Wagenknecht 2020a, 7-24.

Winter M (2014). Topografie der Hochschulforschung in Deutschland. In P Pasternack 2014a, 25-49. 